\title{
The Impacts of Humans And Dogs On The Spatial And Temporal Activity of Wildlife In Urban Woodlands
}

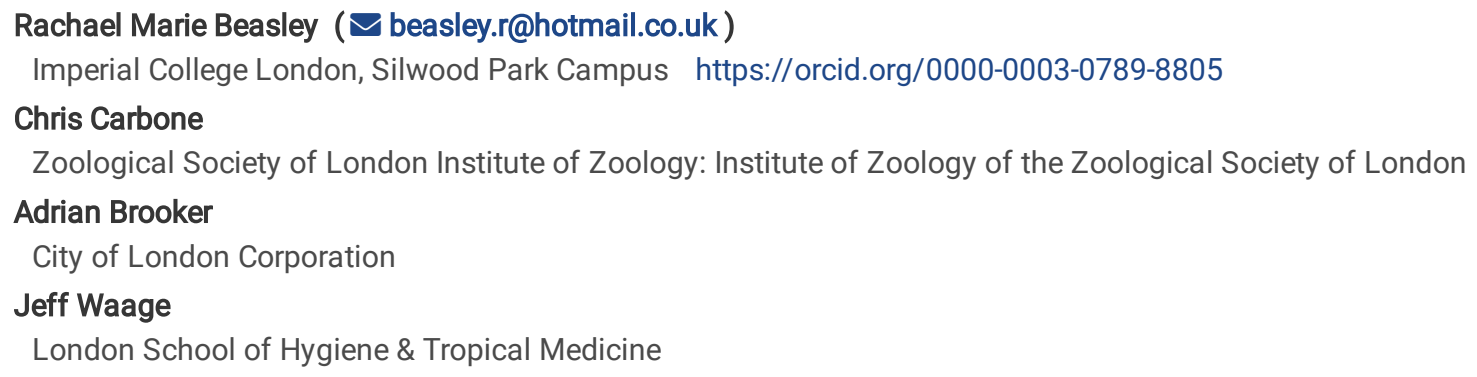




\section{Abstract}

Humans can derive enormous benefit from the natural environment and the wildlife they see there, but increasing human use may negatively impact wildlife, particularly in urban green spaces. Few studies have focused on the trade-offs between intensive human use and wildlife use of shared green spaces in urban areas. In this paper we investigate the impacts of humans and their dogs on wildlife within an urban green space using camera trap data from Hampstead Heath, London. Spatial and temporal activity of common woodland wildlife species were compared between sites with low and high frequency of visits by humans and dogs. Blackbirds (Turdus merula) were found to be significantly more active at sites with lower visitation rates, while red foxes (Vulpes vulpes) were observed more in areas with higher visitation rates. Birds and grey squirrels (Sciurus carolinensis) showed evidence of temporal displacement away from peak periods of human and dog visits in areas where visitation rates were high. Responses observed to human and dog visits could have implications for wildlife species persistence and community composition in urban woodlands.

\section{Introduction}

Enjoyment of green spaces in urban areas is important to mental health and wellbeing, and a key aspect of this effect is the interaction with nature and wildlife (Soulsbury and White, 2015; Triguero-Mas et al, 2015). However, there is growing evidence that recreational use of public green spaces can be a form of human disturbance affecting the abundance, diversity and behaviour of wild species (Larson et al, 2016; Gaynor et al, 2018). Negative effects of human disturbance may be stronger in urban green spaces than in more rural landscapes as resources are more limited and there is less space and time to avoid humans (Gaynor et al, 2018). Understanding how wildlife is impacted by human disturbance in urban green spaces will allow us to develop solutions that minimise negative impacts. This will benefit both wildlife and humans who will potentially have a greater variety and abundance of wildlife species to enjoy (Soulsbury and White, 2015; Triguero-Mas et al, 2015).

Use of urban green spaces like Hampstead Heath is growing as people value time spent outside and in nature. For instance, estimated visits to Hampstead Heath rose from 7 million to 9.3 million between 2007 and 2018 (Intelligent Space ATKINS, 2007, p. 75; City of London, 2019), while the 2020 pandemic appears to have increased visits by $50 \%$ in a single year (City of London, unpublished). When surveyed in 2017 , visitors to the Heath reported enjoyment of nature as the most common reason for their visits (Groundwork London, 2017).

This study examines how the behaviour of wildlife on Hampstead Heath is affected by recreational visits by humans and dogs (Canis familiaris). It is focused on woodland bird and mammal species that forage on the ground, including nocturnal species that have some activity in the morning and evening. Woodlands on our study site, Hampstead Heath, are criss-crossed by a network of walking paths used by visitors. A large proportion of visitors also bring dogs to Hampstead Heath, usually off-leash, which is typical across green spaces in England (Taylor et al, 2005). Few studies on wildlife activity include the effect of visitors accompanied by dogs, but those that do show that dogs, like humans, can further affect wildlife activity (Fernández-Juricic and Tellería, 2000; Dowding et al, 2010; Banks and Bryant 2007; Reilly et al, 2017). As dogs, even those off-leash, are found in close association with humans, we combined the visits of humans and dogs and analysed how wildlife species responded to the overall presence of both species. We hypothesised that wildlife species would be observed less in areas of woodland with high frequency of human and dog visits, and would shift their temporal activity patterns in those areas to avoid this form of disturbance. We expected this effect to be stronger for diurnal than nocturnal species.

We tested whether visiting humans and dogs affect the behaviour of wildlife species using camera traps. Camera traps provide a unique opportunity to understand small scale patterns in temporal and spatial overlap and interactions across species within vertebrate communities (Rowcliffe and Carbone, 2008) and are increasingly used at a range of scales from local communities to global-scale meta-analyses (Steenweg et al, 2016). For this study, we utilised images from a 2018 camera trap survey set up to study hedgehogs by the London HogWatch Project (Carbone and Cates, 2018). This survey captured activity of species foraging on woodlands based on a systematic grid-based camera survey (see Rowcliffe et al, 2014). By recording continuous photographic data across multiple independently selected woodland sites, we were able to obtain unbiased spatial and temporal information on wildlife occurrence and activity in areas that differed in levels of human and dog visitation.

\section{Methods}

\section{Study Area}

Hampstead Heath is a 275-hectare urban green space, which is listed as a site of Metropolitan Importance for Nature Conservation and situated in a densely populated part of Central London (City of London, 2019). Hampstead Heath comprises a mosaic of habitats including woodland, grassland, scrub and open water, which are managed to maintain a diverse and biodiverse landscape while ensuring access by visitors (City of London, 2010; City of London, 2019). Wildlife surveys show woodlands, including an ancient woodland designated as a Site of Special Scientific Interest (Natural England 1990), to be particularly rich in breeding bird and mammal species (City of London, unpublished).

\section{Data Collection}

Between $18^{\text {th }}$ April and $5^{\text {th }}$ July 2018 , camera traps were uniformly distributed over Hampstead Heath across 150 sites using a 150 m² cell-size 
grid overlay (Monterroso et al, 2013). Each camera trap operated on average for 15 days (range: 9 - 23 days) and recorded continuously 24 hours a day. Survey lengths varied due to limited storage on memory cards, batteries running out of charge and camera failures. Camera traps were attached $20-50 \mathrm{~cm}$ above the ground to suitable features nearest to the ideal coordinates, for example fence posts or trees. Traps were angled slightly downwards to increase the probability of recording wildlife. Traps minimised disturbance by passively detecting wildlife using heat signatures (Welbourne et al, 2016) and were not baited. 104 camera traps across four models were used: 64 Browning Strike Force HD-Pro BTC-131 5HDPs, 20 Reconyx HyperFire HC-500s, 10 Reconyx Hyperfire HC-600s and 10 Reconyx Hyperfire PC-800s. The Browning model took one image per trigger with a delay of approximately 0.6 seconds between photos, while the Reconyx models took ten images per trigger with a delay of one second (specifications for these cameras can be found at www.trailcampro.com).

\section{Camera Site Selection}

For the purpose of this study, a subset of 26 camera traps were selected from woodland sites across Hampstead Heath (Online Resource-Table 1). Camera traps were selected in woodland designated as "at least $84 \%$ broadleaved woodland", with the exception of one camera in a wooded copse in "semi-neutral improved grassland" (City of London, 2009; Online Resource-Table 2). Broadleaved woodland sites were dominated by English oak (Quercur robur) and less frequently by common beech (Fagus sylvatica) and sessile oak (Quercus petraea), with an understory of bramble (Rubus fruticosus), holly (Ilex aquifolium) and other small trees, and a ground cover of common ivy (Hedera helix) or bracken (Pteridium aquilinum) (See Online Resource-Table 2 for full habitat descriptions by site). Within this habitat, all camera traps were positioned to give a clear view of open leaf litter to five metres with little ground cover under a closed canopy. This improved the detection probability for all wildlife species, especially hedgehogs which can go undetected in tall vegetation (Sollmann et al, 2013). Importantly, the distribution of cameras across the Heath meant some were close to, and others distant from, foot paths. Some were in the few fenced off woodland areas on the Heath, which people and dogs rarely visited. This created a broad range in frequency of human and dog visits recorded between traps.

\section{Photo Review}

All vertebrate species within camera images were manually identified using ExifPro v2.1 (Kowalski, 2013) and classed as 'detections' and/or 'contacts'. When an animal enters a camera's field of view, the camera triggers and takes a series of successive images of the animal. Each successive image of that animal was classed as a 'detection', while the first image, indicating the arrival of a new individual, was classed as a 'contact'. Hence a contact was often the first image in a series of detections for an individual of a particular species. While the sum of all detections from a specific trap gives a measure of the total time spent by that species at that site, the sum of contacts estimates the total number of individuals of that species visiting the site. To estimate contacts, we assumed that an interval of two or more minutes between successive detections of a species represents the arrival of a new individual (Kay and Parson, 2014). For wildlife species, humans and dogs, we recorded total contacts as an indicator of visits to a particular site. Dogs on and off leads were both counted as contacts.

\section{Wildlife Selection}

Across the 26 camera traps, images of 18 distinct species of wildlife were captured, with some species being particularly common (Table 1 ). Diurnal species included a range of ground-foraging birds and grey squirrels (Sciurus carolinensis), while nocturnal species included mostly red foxes (Vulpes vulpes) and European hedgehogs (Erinaceus europaeus). For our analysis of wildlife activity, we put species in groups (All Birds and Non-diurnal Mammals) and also investigated individual species where we had enough detections.

Table 1 Summary of wildlife species detected in camera images across the 26 sites, with the number of absolute and relative detections (out of total 13,617 wildlife detections), and the number of sites at which the species was detected in camera images.

\begin{tabular}{|c|c|c|c|c|}
\hline Common Species Name & Latin Name & Total Number of Detections & Proportion of Wildlife Detections & Total Sites \\
\hline Common Blackbird & Turdus merula & 1,646 & $12 \%$ & 19 \\
\hline Magpie & Pica pica & 999 & $7 \%$ & 21 \\
\hline Song Thrush & Turdus philomelos & 478 & $4 \%$ & 13 \\
\hline Wood Pigeon & Columba palumbus & 956 & $7 \%$ & 12 \\
\hline Other Birds ${ }^{a}$ & - & 501 & $4 \%$ & 18 \\
\hline European Hedgehog & Erinaceus europaeus & 482 & $4 \%$ & 18 \\
\hline Grey Squirrel & Sciurus carolinensis & 6,402 & $47 \%$ & 26 \\
\hline Red Fox & Vulpes vulpes & 1,769 & $13 \%$ & 24 \\
\hline Other Mammals ${ }^{\mathrm{b}}$ & - & 386 & $3 \%$ & 10 \\
\hline
\end{tabular}


Table 1 footnotes: ${ }^{a}$ 'Other birds' consists of blue tits (Cyanistes caeruleus), carrion crows (Corvus corone), dunnocks (Prunella modularis), Eurasian jays (Garrulus glandarius), great tits (Parus major), European robins (Erithacus rubecula) and wrens (Troglodytes troglodytes), which individually have very few tags and often were present at only a few sites.

b 'Other mammals' consists of brown rats (Rattus norvegicus), wood mice (Apodemus spp.), European rabbits (Oryctolagus cuniculus) and muntjacs (Muntiacus reevesi), which individually have very few tags and were present at only a few sites.

More frequently observed species were also better represented over a range of sites with different levels of humans and dog visits. Based on total detections, we selected four bird species for individual analysis: common blackbirds (Turdus merula), magpies (Pica pica), song thrushes (Turdus philomelos), and wood pigeons (Columba palumbus). We also created for analysis the category "All Birds" in order to incorporate these species and the individually rare but collectively significant diversity of "Other Birds" (Table 1). Three species of mammals were analysed individually: red foxes, grey squirrels and European hedgehogs. Because mammal species were, broadly speaking, either diurnal, crepuscular or nocturnal, and likely respond to differently to daytime visits by humans and dogs (Gaynor et al, 2018), we created for analysis a group of "Nondiurnal Mammals" comprising red foxes, European hedgehogs, wood mice (Apodemus sylvaticus), European rabbits (Oryctolagus

cuniculus) and muntjac (Muntiacus reevesi). Grey squirrels were the only diurnal mammal species analysed. Camera trap records of brown rats showed them to be predominantly diurnal (Online Resource-Figure 1b), but their numbers were so few that they were excluded from the analysis.

\section{Statistics}

\section{Establishing sites of low and high human and dog visits}

Human and dog contacts, separately recorded at each site, were summed and divided by the time of operation of the camera at each site to generate Relative Abundance Indices (RAls) in contacts per day (Carbone et al, 2001). We justify the use of these "Human + Dog RAls" on the basis that dogs were not seen without humans, and the effects of both on wildlife could not be easily separated. Human and dog visits were highly correlated (simple linear regression with logged RAls: $b=0.67, p$-value $<0.01, R^{2}=0.70$; Online Resource-Table 3 and Figure 2).

Human + Dog RAls per site ranged from zero for cameras in remote, fenced areas to 127 contacts day ${ }^{-1}$ for cameras near busy paths. Examining all sites, we identified a natural breakpoint between four and eight human and dogs contacts per day (Reilly et al, 2017; Online Resource-Figure 3). Sites with less than five humans and dogs contacts per day were defined as low visit sites $\left(n=17\right.$, median $=2$ contacts day $\left.{ }^{-1}\right)$, while sites with five or more human and dogs contacts per day were defined as high visit sites $\left(n=9\right.$, median $=13$ contacts day $\left.{ }^{-1}\right)$.

\section{Spatial Displacement}

To determine potential spatial displacement, RAls were also calculated for wildlife species at each site. Wildlife RAls were put into low and high visit site groups and the two groups compared using Wilcoxon tests, due to the general non-homogeneity of variances, lack of normality and unequal group sizes.

\section{Temporal Displacement}

To examine temporal displacement of wildlife by human and dog visits, we calculated at each site the degree of temporal overlap between Human + Dog detections and the detections for different wildlife species, and then compared these results between our low and high visit sites. We assumed that at low visit sites, where human and dog disturbance is less, the observed activity schedules are more likely to reflect the natural times of activity for a species. Hence, reduced temporal overlap at high visit sites would mean that species are being displaced from their natural activity schedules (Reilly et al, 2017).

To calculate temporal displacement, detections were used, rather than contacts, as the method requires total species activity and does not need to distinguish individuals (Rowcliffe et al, 2014). Camera models differed in photographic rate, meaning that they generated different numbers of detections in response to a species crossing in front of the camera. By filtering the data so that only detections recorded at least one minute apart were included in the analysis, these camera differences were removed (note: measuring spatial displacement did not require correcting for camera differences as it utilised contacts, which are at least two minutes apart).

Timestamps were then converted to sunTime to standardise how sunrise and sunset varied between $18^{\text {th }}$ April and $11^{\text {th }}$ June across the 26 sites: times at sunrise and sunset were standardised to $\pi / 2$ and $3 \pi / 2$ respectively. This corrected for changes in timings of behaviour due to the seasonal photoperiod change (Nouvellet et al, 2012; Meredith and Ridout, 2020).

Temporal overlap estimates were generated using the R package 'Overlap' (Ridout and Linkie, 2009; Meredith and Ridout, 2020). 'Overlap' converts sunTime, in radians, into non-parametric kernel density estimates for each species, i.e. activity schedules (Ridout and Linkie, 2009; Meredith and Ridout, 2020). The activity schedule across 24 hours of each species is then superimposed with that generated for combined 
humans and dogs. The area underneath where the two activity schedules overlap is the temporal overlap estimate, which has a value between 0 and 1 that represents no and complete temporal overlap respectively (Ridout and Linkie, 2009; Meredith and Ridout, 2020).

To be selected for individual analysis, a species needed to have at least ten detections to produce robust estimates of temporal activity (DíazRuiz et al, 2016). If either species (i.e. a wildlife species or humans + dogs) in the temporal overlap analysis had less than 75 detections, density estimates were generated using the Dhat1 estimator with a smoothing coefficient of 0.8 (Meredith and Ridout 2020). This estimator compensates for the reduced number of detections by over smoothing the activity schedule to increase its overall accuracy (Ridout and Linkie, 2009). Alternatively, the Dhat4 estimator was used which has a smoothing coefficient of 1 . To estimate the accuracy of the temporal overlap estimates, we generated 95\% confidence intervals by recalculating the temporal overlap estimates 1,000 times using bootstrapping (Meredith and Ridout, 2020).

Finally, temporal overlap estimates between each wildlife species and humans and dogs were compared between low and high visit sites using Wald Chi-Squared tests. The formula for which is as follows:

$$
\text { Wald } \chi^{2}=\frac{\left(T_{H}-T_{L}\right)^{2}}{\left(s e_{H}-s e_{L}\right)^{2}}
$$

where $T_{H}$ and $T_{L}$ are the temporal overlap estimates from high and low visit sites, respectively, and se $\mathrm{H}_{\mathrm{H}}$ and $\mathrm{se}_{\mathrm{L}}$ are the standard errors of these estimates from high and low visit sites, respectively. Using a degree of freedom of one, temporal overlap estimates from low and high visit sites were statistically significant if the chi-squared value was greater than 3.841 ( $p$-value $<0.05$ ).

All plotting and analyses were conducted in R v.3.6.2 (R Core Team, 2019).

\section{Results}

Across 26 sites, the total trapping effort was 389 days. In total, 13,617 wildlife detections of 18 species (Table 1), and 18,156 detections of humans and dogs were recorded, with 10,897 human detections and 7,259 dog detections. In low visit sites, the median and mean Human + Dog RAI were 1.52 contacts day ${ }^{-1}(95 \% \mathrm{CI}[0.22,2.81])$ and 1.47 contacts day ${ }^{-1}$, respectively, while in high activity sites they were 13.23 contacts day $^{-}$ 1 (95\% $\mathrm{Cl}[8.83,126.57])$ and 28.14 contacts day ${ }^{-1}$ respectively.

\section{Spatial Displacement}

Results are shown in Table 2. Blackbirds had significantly lower RAls in high visit sites than in low visit sites, while all bird species combined (All Birds) and other individual species did not show a significant difference. For mammals, red foxes had significantly higher RAls in high visit sites, while European hedgehogs and grey squirrels showed no significant differences. Non-diurnal Mammals also showed increased RAls at high visit sites, although this difference was not statistically significant and strongly influenced by fox detections.

Table 2 Median (Mean) Relative Abundance Indices of each wildlife species in low and high visit sites, and results from Wilcoxon tests comparing RAls between low and high visit sites. Significant if p-value $<0.05$ (in bold). Confidence intervals shown for medians only as data is not normally distributed. 


\begin{tabular}{|c|c|c|c|c|c|c|}
\hline Species & $\begin{array}{l}\text { Median RAls [95\% Cl] (low } \\
\text { visits; contacts day }{ }^{-1} \text { ) }\end{array}$ & $\begin{array}{l}\text { Mean RAls (low } \\
\text { visits; contacts day- } \\
\text { 1) }\end{array}$ & $\begin{array}{l}\text { Median RAls [95\% Cl] } \\
\text { (high visits; contacts day } \\
\text { 1) }\end{array}$ & $\begin{array}{l}\text { Mean RAls (high } \\
\text { visits; contacts day' } \\
\text { 1) }\end{array}$ & $\begin{array}{l}\text { W } \\
\text { statistic }\end{array}$ & $\mathrm{P}_{\text {value }}$ \\
\hline All Birds & $1.36[0.64,4.18]$ & 2.29 & $0.80[0.11,5.63]$ & 1.46 & 49 & 0.15 \\
\hline Blackbird & $0.58[0.12,3.42]$ & 1.07 & $0.00[0.00,5.07]$ & 0.12 & 27 & $<0.01$ \\
\hline Magpie & $0.15[0.06,0.58]$ & 0.28 & $0.29[0.00,5.07]$ & 0.98 & 83 & 0.75 \\
\hline $\begin{array}{l}\text { Song } \\
\text { Thrush }\end{array}$ & $0.08[0.00,0.43]$ & 0.32 & $0.00[0.00,0.86]$ & 0.12 & 59 & 0.33 \\
\hline $\begin{array}{l}\text { Wood } \\
\text { Pigeon }\end{array}$ & $0.00[0.00,0.17]$ & 0.22 & $0.11[0.00,0.47]$ & 0.14 & 98.5 & 0.21 \\
\hline $\begin{array}{l}\text { Non-diurnal } \\
\text { Mammals }\end{array}$ & $1.02[0.40,1.72]$ & 0.96 & $1.36[0.96,3.52]$ & 1.74 & 113 & 0.05 \\
\hline $\begin{array}{l}\text { European } \\
\text { Hedgehog }\end{array}$ & $0.14[0.00,0.37]$ & 0.18 & $0.14[0.00,0.99]$ & 0.21 & 73.5 & 0.89 \\
\hline $\begin{array}{l}\text { Grey } \\
\text { Squirrel }\end{array}$ & $1.62[0.72,3.70]$ & 2.58 & $1.52[0.45,4.66]$ & 1.72 & 63 & 0.49 \\
\hline Red Fox & $0.36[0.07,1.02]$ & 0.51 & $1.13[0.60,3.52]$ & 1.50 & 129 & $<0.01$ \\
\hline
\end{tabular}

\section{Temporal Displacement}

Fig. 1 Activity schedules showing the temporal overlap between Human + Dogs (blue solid) and a) All Birds, b) Blackbirds, c) Magpies, d) Song Thrushes, e) Wood Pigeons, f) Non-diurnal Mammals, g) Red Foxes, h) European Hedgehogs and i) Grey Squirrels (red dashed) in low visit sites (left column) and high visit sites (right column). For number of detections for each species, see Online Resource-Table 4 . Figures made in $R$ v3.6.2 (R Core Team, 2019)

Figure 1 shows the activity schedule of wildlife species at low and high visit sites. Note that the temporal distribution of Human + Dog detections varies between these categories, probably because dog walkers tend to use morning hours more than people walking on their own or in groups. Statistical analysis is shown in Table 3 (see also Online Resource-Table 4). All bird species combined (All Birds) showed significant temporal displacement at high visit sites with $22 \%$ less temporal overlap with humans and dogs than in low visit sites. Individually, blackbirds, wood pigeons and grey squirrels were significantly temporally displaced with $22 \%, 18 \%$ and $26 \%$ less temporal overlap at high visit sites, respectively. Magpies, song thrushes, red foxes, European hedgehogs and Non-diurnal Mammals showed no significant temporal displacement (Table 3, Figure 1, and Online Resource-Table 4)

Table 3 Summary of results from temporal displacement analysis: Temporal overlap estimates between humans and dogs and each wildlife species by low and high visit sites. Temporal overlap estimates range between 0 (no overlap) and 1 (complete overlap). Wald statistics from comparison of temporal overlap between human and dog visit sites and each wildlife species or group. Significant p-values $(<0.05)$ in bold.

\begin{tabular}{|lllll|}
\hline Species & Temporal Overlap-Low Visit [95\% Cl] & Temporal Overlap-High Visit [95\% Cl] & Wald Statistic & p-value \\
\hline All Birds & $0.93[0.88,0.96]$ & $0.73[0.67,0.79]$ & 32.13 & $<0.001$ \\
\hline Blackbird & $0.92[0.87,0.97]$ & $0.72[0.57,0.86]$ & 7.02 & 0.01 \\
\hline Magpie & $0.76[0.65,0.86]$ & $0.68[0.60,0.76]$ & 1.48 & 0.22 \\
\hline Song Thrush & $0.75[0.65,0.85]$ & $0.72[0.54,0.85]$ & 0.12 & 0.73 \\
\hline Wood Pigeon & $0.89[0.81,0.96]$ & $0.73[0.55,0.88]$ & 4.08 & 0.04 \\
\hline Non-diurnal Mammals & $0.10[0.06,0.14]$ & $0.08[0.05,0.10]$ & 0.12 & 0.73 \\
\hline European Hedgehog & $0.07[0.02,0.12]$ & $0.06[0.01,0.12]$ & 0.04 & 0.84 \\
\hline Grey Squirrel & $0.85[0.80,0.91]$ & $0.63[0.58,0.69]$ & 29.96 & $<0.01$ \\
\hline Red Fox & $0.12[0.08,0.17]$ & $0.08[0.05,0.10]$ & 2.27 & 0.13 \\
\hline
\end{tabular}

\section{Discussion}

Our study examined the patterns of spatial and temporal displacement in birds and mammals in sites with low and high human and dog visits. As predicted, we found that diurnal wildlife showed greater tendency for spatial and temporal displacement in response to diurnal human and 
dog visits compared to nocturnal species. Our results indicate that not all species were impacted uniformly. Table 4 summarises patterns of spatial and temporal displacement across all species and species groups.

Table 4 Summary of trends observed in spatial and temporal overlap. For spatial overlap, mean RAls for high visit sites for each group and species (Table 2) are marked as reduced (-), increased (+) or unchanged (=) relative to low visit sites where differences in means exceed $20 \%$. The same criteria are applied to temporal overlap estimates (Table 3). Significant differences at $p<0.05\left(^{\star}\right)$ and $p<0.01(\star \star)$ are shown.

\begin{tabular}{|lll|}
\hline Species & Spatial overlap & Temporal overlap \\
\hline All Birds & $(-)$ & $(-)^{* \star}$ \\
\hline Blackbird & $(-)^{* *}$ & $(-)^{* *}$ \\
\hline Magpie & $(-)$ & $(-)$ \\
\hline Song Thrush & $(-)$ & $(-)$ \\
\hline Wood Pigeon & $(+)$ & $(-) *$ \\
\hline Grey Squirrel & $(-)$ & $(-) * *$ \\
\hline Non-diurnal Mammals & $(+)$ & $(-)$ \\
\hline European Hedgehog & $(=)$ & $(=)$ \\
\hline Red Fox & $(+) * *$ & $(-)$ \\
\hline
\end{tabular}

Many factors determine the activity of wildlife species in woodlands, including the local distribution of vegetation, food and water resources, and the location of burrows and nest sites. We measured one factor, the effects of visits by humans and dogs, and sought to control for other factors by selecting traps located in a specific vegetation type and microhabitat. Studies on the ecology of species observed corroborate their natural association with broadleaved woodland floors and their habit of foraging in leaf litter. This is an important microhabitat for blackbirds and song thrush (Carpenter et al, 2009), and one which is frequently used for foraging by wood pigeon (Robinson, 2005) and magpie (Birkhead, 2010). Broadleaved woodland floors are also used for foraging by squirrels (Gurnell,1987; Kenward et al, 1998), foxes (Sidorovich et al, 2006) and hedgehogs (Riber, 2006). We focus our discussion on abundant wildlife species which were observed at more than half of all sites, making it more likely that differences seen related to human and dog visitation rather than other factors.

Blackbirds showed significant spatial and temporal displacement from high visit sites: less individuals were recorded in high visit sites and those that were recorded shifted their activity patterns to early morning, when human and dog visits were less frequent. Spatial displacement was not found for other bird species, but significant temporal displacement was found for the group 'All Birds', where detections of all bird species were pooled, and for woodpigeons. Generally, in low visit sites, all bird species showed a roughly midday peak in activity on the woodland floor, with the exception of song thrushes which exhibited a morning and evening activity peak. At high visit sites, the daytime peaks for all bird species were retained but diminished, and a separate, distinctive early morning activity peak appeared.

Magpies were the only bird species which showed a trend towards being more common in high visit sites, although the difference was not significant. Like some other corvids, this species is known to be anthropophilic (Gutzwiller et al, 2002; Larson et al, 2016), which may be related to their tendency to scavenge human food (Jerzak, 2001; Storch and Leidenberger, 2003) and to exploit the disruption of other birds by humans to find and predate on their nests (Groom, 1993; Gutzwiller et al, 2002; Marzluff and Neatherlin, 2006).

Our results for blackbirds are similar to those found by Fernández-Juricic and Tellería (2000) in city parks in Madrid. Using behavioural observation methods, they found that parks with more human and dog visits had fewer foraging blackbirds and that blackbirds were less frequently present at times of the day when visitors peaked (Fernández-Juricic and Tellería, 2000). The more common species in this study, including blackbirds, magpie and wood pigeons, were also less abundant in sections of parks with greater human disturbance (FernándezJuricic, 2000). van der Zande and Vos (1984) also found evidence that recreational visits decreased local activity of blackbirds, song thrushes and wood pigeons in a wooded lakeside habitat in the Netherlands.

The only strictly diurnal mammal included in our study, grey squirrel, showed no spatial displacement at high visit sites but strong temporal displacement. Like birds, squirrels had a broad, daytime activity peak in low visit sites, but at high visit sites, this changed to two distinctive peaks before and after the main period of human and dog activity. As far as we are aware, our study provides the first evidence of how humans and dogs affect the temporal activity of grey squirrels.

Non-diurnal Mammals showed no spatial or temporal displacement in areas of high human and dog visits. In fact, foxes made significantly more visits to these areas, which probably accounted as well for the trend in Non-diurnal Mammals. Other studies have shown a positive spatial association between humans and foxes (Prange et al, 2004; Kays and Parsons, 2014; Oberosler et al, 2017; Reilly et al, 2017), which may reflect

Page $7 / 11$ 
attraction to food left by humans or greater abundance of natural foods, such as invertebrates and earthworms, created by path disturbance (Harris, 1981; Contesse et al, 2004). This study suggests that normal, diurnal recreation by humans with dogs does not displace hedgehogs, even in high visit areas. By contrast, a study on hedgehog activity associated with more intensive and nocturnal human activity at a music festival, demonstrated spatial and temporal displacement (Rast et al, 2019).

By displacing wildlife species in space or time, human disturbance on Hampstead Heath could be impacting the ability of the affected species to forage effectively, and hence reducing their reproductive success (Ditchkoff et al, 2006; Diaz-Ruíz et al, 2016; Larson et al, 2016; Gaynor et al, 2018). There is evidence that recreational use of trails in natural woodlands decreases both bird activity and breeding (van der Zande and Vos 1984; Bötsch et al. 2017, Bötsch et al. 2018). While our study only found significant displacement for quite common species like blackbirds and squirrels, similar displacement of less common species may have more impact on their survival and persistence. On Hampstead Heath, for instance, song thrush and mistle thrush (Turdus viscivorus) are nationally declining species (Burns et al, 2020) that forage in the same woodland floor habitat as blackbirds, but nesting bird surveys in 2020 and 2021 show that they are considerably less common (City of London, unpublished). They were not well captured in this study, but more focused camera trapping might determine how they are affected by human and dog visits.

Camera traps have a history of being used to study rare, widely ranging mammals in remote areas, but have seldom been used in urban green spaces and to study birds and common urban mammals. This study shows their potential value to the study of small-scale spatiotemporal patterns of habitat use in response to disturbance, at both the individual species and community level. Using camera traps overcomes the problems of more typical focal observations, including any bias from the presence of a human observer and the limited time period for such observations. This results in more accurate observations of wildlife activity and increases the likelihood of capturing long term changes to it. However, our study does have other limitations which need highlighting.

Most importantly, other factors may have influenced wildlife activity besides disturbance by humans and their dogs. While we could not correct for potentially confounding factors, we sought to reduce their impact by selecting woodland sites with very similar plant composition and microhabitats, and by focusing on common and widespread species. Secondly, Hampstead Heath is not a typical urban green space as it is exhibits both high ecological diversity and intense recreational use, which may limit the general applicability of our findings. Finally, in measuring wildlife responses against the combined presence of humans and dogs, we were unable to examine their potentially different effects. For instance, dog walking was more frequent in the morning (Online Resource-Figure 2) when we also saw the most striking temporal displacement of birds and squirrels, implying dogs may have a disproportionate impact on wildlife.

In conclusion, our study provides evidence that the spatial and temporal activity of some woodland species in urban green spaces is changed as a result of recreational visits by human and their dogs. Further research should focus on the implications of this disturbance for local wildlife populations and their reproductive success, particularly for more vulnerable species, and on the separate effects of humans and dogs, in order to identify specific approaches to reducing impacts from recreational visits in urban green spaces on biodiversity.

\section{Declarations}

\section{Funding}

The data collection using camera traps was majorly funded by the British Hedgehog Preservation Society, the People's Trust for Endangered Species, and the Pauline Meredith Charitable Trust. CC was funded by Research England.

\section{Conflicts of Interest}

The authors have no conflicts of interest to declare.

\section{Availability of Data and Material}

The original images and resulting dataset are not publicly available to protect the privacy of those recorded.

\section{Code Availability}

All code is currently available by request from the corresponding author.

\section{Author's Contributions}

Jeff Waage, Chris Carbone and Rachael Beasley contributed to the study conception and design. Data collection was performed by Chris Carbone and Adrian Brooker. Analysis was performed by Jeff Waage and Rachael Beasley. The first draft of the manuscript was written by Rachael Beasley and Jeff Waage. All authors commented and edited previous versions of the manuscript. All authors read and approved the final manuscript. 


\section{Ethics Approval/Consent to Participate/Consent for Publication}

Signs were placed around Hampstead Heath informing visitors that camera traps were in use. No effort was or will be made to identify visitors recorded by the camera traps.

\section{References}

1. Banks PB, Bryant JV (2007) Four-legged friend or foe? Dog walking displaces native birds from natural areas. Biol. letters. 3(6), 611-613. https://doi.org/10.1098/rsbl.2007.0374.

2. Birkhead T (2010) The Magpies: The Ecology and Behaviour of Black-billed and Yellow-billed Magpies. London: Poyser Monographs ISBN10 : 1408140241. ISBN-13: 978-1408140246

3. Bötsch Y, Tablado Z, Jenni L (2017) Experimental evidence of human recreational disturbance effects on bird-territory establishment. Proc. R. Soc. B 284: 20170846. https://doi.org/10.1098/rspb.2017.0846

4. Bötsch Y, Tablado Z, Scherl D, Kery M, Graf R.F, Jenni, L. (2018) Effect of Recreational Trails on Forest Birds: Human Presence Matters. Front. Ecol. Evo. 6:175. https://doi.org/10.3389/fevo.2018.00175

5. Burns F, Eaton MA, Balmer DE, Banks A, Caldow R, Donelan JL, Douse A, Duigan C, Foster S, Frost T, Grice PV, Hall C, Hanmer HJ, Harris SJ, Johnstone I, Lindley P, McCulloch N, Noble DG, Risely K, Robinson RA, Wotton S (2020) The state of the UK's birds 2020. The RSPB, BTO, WWT, DAERA, JNCC, NatureScot, NE and NRW, Sandy, Bedfordshire.

6. Carbone C, Christie S, Conforti K, Coulson T, Franklin N, Ginsberg JR, ... Shahruddin WN (2001). The use of photographic rates to estimate densities of tigers and other cryptic mammals. Anim. Conserv. 4(1), 75-79. https://doi.org/10.1017/S1367943001001081

7. Carbone C, Cates R (2018) LONDON HOGWATCH Hampstead Heath camera-trap survey April- July 2018. Zoological Society of London. http://democracy.cityoflondon.gov.uk/documents/s122517/Appendix\%202\%20-

\%20Hampstead\%20Heath\%20Survey\%202018\%20Report.pdf Accessed 27 February 2020

8. Carpenter R, Charman E, Smart J, Amar A, Gruar D, Grice P (2009) Habitat associations of woodland birds II. RSPB Research Report No. 36. ISBN 978-1-905601-20-2.

9. City of London (2009) Phase 1 Habitat Survey data of Hampstead Heath, London 2008-2009 [data file].

10. City of London (2010) Hampstead Heath management plan Part II. Topic Paper 2: The Natural Landscape. City of London.

11. City of London (2019). Hampstead Heath Management Strategy 2018 to 2028. City of London. https://www.cityoflondon.gov.uk/assets/Green-Spaces/hampstead-heath-strategy.pdf Accessed 14th July 2020

12. Contesse P, Hegglin D, Gloor S, Bontadina F, Deplazes P (2004) The diet of urban foxes (Vulpes vulpes) and the availability of anthropogenic food in the city of Zurich, Switzerland. Mamm. Biol. 69(2), 81-95. https://doi.org/10.1078/1616-5047-00123

13. Díaz-Ruiz F, Caro J, Delibes-Mateos M, Arroyo B, Ferreras P (2016) Drivers of red fox (Vulpes vulpes) daily activity: prey availability, human disturbance or habitat structure? J Zool. 298: 128-138. https://doi.org/10.1111/jzo.12294

14. Ditchkoff SS, Saalfeld ST, Gibson CJ (2006). Animal behavior in urban ecosystems: modifications due to human-induced stress. Urban Ecosyst. 9: 5-12. https://doi.org/10.1007/s11252-006-3262-3

15. Dowding CV, Harris S, Poulton S, Baker PJ (2010) Nocturnal ranging behaviour of urban hedgehogs, Erinaceus europaeus, in relation to risk and reward. Anim.I Behav. 80(1): 13-21. https://doi.org/10.1016/j.anbehav.2010.04.007

16. Fernández-Juricic $E$ (2000) Local and regional effects of pedestrians on forest birds in a fragmented landscape. The Condor. 102, $247-255$. https://doi.org/10.1093/condor/102.2.247

17. Fernández-Juricic E, Tellería JL (2000) Effects of human disturbance on spatial and temporal feeding patterns of Blackbird Turdus merula in urban parks in Madrid, Spain. Bird Study. 47:1, 13-21, https://doi.org/10.1080/00063650009461156

18. Gaynor KM, Hojnowski CE, Carter NH Brashares JS (2018). The influence of human disturbance on wildlife nocturnality. Science. 360(6394): 1232-1235. https://doi.org/10.1126/science.aar7121

19. Groom DW (1993) Magpie Pica pica predation on Blackbird Turdus merula nests in urban areas. Bird Study. 40, 55-62. https://doi.org/10.1080/00063659309477129

20. Groundwork London (2017) Hampstead Heath Community Vision Report. City of London. https://democracy.cityoflondon.gov.uk/documents/s81923/Appendix\%202A\%20Heath\%20Community\%20Vision\%20Results\%20Report.pdf Accessed $18^{\text {th }}$ November 2020.

21. Gurnell J (1987) The natural history of squirrels. London: Christopher Helm.

22. Gutzwiller K J, Riffell SK, Anderson SH (2002) Repeated human intrusion and the potential for nest predation by gray jays. J. Wildlife Manage. 66:372-380. https://doi.org/10.2307/3803170

Page 9/11 
23. Harris S (1981) The food of suburban foxes (Vulpes vulpes), with special reference to London. Mammal Rev. 11,151-168. https://doi.org/10.1111/j.1365-2907.1981.tb00003.x

24. Intelligent Space ATKINS (2007) Hampstead Heath Observation Studies, Pedestrian and Cycle Review for the City of London, 20 December 2007. p. 75. London: Intelligent Space ATKINS.

25. Jerzak L (2001) 'Synurbanization of the Magpie in the Palearctic'in Marzluff JM, Bowman R, and Donnelly R (eds.) Avian Ecology and Conservation in an Urbanizing World. Kluwer Academic, Norwell, MA: Kluwer Academic, pp. 405-42

26. Kays R and Parsons AW (2014) Mammals in and around suburban yards, and the attraction of chicken coops. Urban Ecosyst. 17(3): 691705. https://doi.org/10.1007/s11252-014-0347-2

27. Kenward R, Hodder K, Rose R, Walls C, Parish T, Holm J, Morris P, Walls S, Doyle F (1998) Comparative demography of red squirrels (Sciurus vulgaris) and grey squirrels (Sciurus carolinensis) in deciduous and conifer woodland. J. Zool., 244: 7-21. https://doi.org/10.1111/j.14697998.1998.tb00002.x

28. Kowalski M (2013). ExifPro (v 2.1) http://www.exifpro.com/ Accessed 20 April 2020.

29. Larson CL, Reed S.E, Merenlender AM, Crooks KR (2016) Effects of Recreation on Animals Revealed as Widespread through a Global Systematic Review. PLOS ONE11(12): e0167259. https://doi.org/10.1371/journal.pone.0167259

30. Marzluff JM, Neatherlin E (2006) Corvid response to human settlements and campgrounds: Causes, consequences, and challenges for conservation. Biol Conserv. 130(2):301-314 https://doi.org/10.1016/j.biocon.2005.12.026

31. Meredith M, Ridout MS (2020) Overview of the overlap package. https://cran.r-project.org/web/packages/overlap/vignettes/overlap.pdf. Accessed 15th July 2020.

32. Monterroso P, Alves PC, Ferreras P (2013) Catch me if you can: diel activity patterns of mammalian prey and predators. Ethology. 119(12), 1044-1056. https://doi.org/10.1111/eth.12156

33. Natural England (1990) Hampstead Heath Woods SSSI. https://designatedsites.naturalengland.org.uk/sitedetail.aspx? SiteCode=S1003451\&SiteName=\&countyCode=\&responsiblePerson=\&unitld=\&SeaArea=\&IFCAArea= Accessed 31 July 2020.

34. Nouvellet P, Rasmussen GSA, Macdonald DW, Courchamp F (2012) Noisy clocks and silent sunrises: measurement methods of daily activity pattern. J. Zool. 286(3): 179-184. https://doi.org/10.1111/j.1469-7998.2011.00864.x

35. Oberosler V, Groff C, Lemma A, Pedrini P, Rovero F (2017) The influence of human disturbance on occupancy and activity patterns of mammals in the Italian Alps from systematic camera trapping. Mamm. Biol. 87: 50-61. https://doi.org/10.1016/j.mambio.2017.05.005.

36. Prange S, Gehrt SD, Wiggers EP (2004) Influences of anthropogenic resources on raccoon (Procyon lotor) movements and spatial distribution. J Mammal. 85(3):483-490. https://doi.org/10.1644/1383946

37. R Core Team (2019) R: A language and environment for statistical computing. R Foundation for Statistical Computing, Vienna, Austria. URL https://www.R-project.org/.

38. Rast W, Barthel L, Berger A (2019) Music Festival Makes Hedgehogs Move: How Individuals Cope Behaviorally in Response to HumanInduced Stressors. Animals: an open access journal from MDPI. 9(7): 455. https://doi.org/10.3390/ani9070455

39. Reilly ML, Tobler MW, Sonderegger DL, Beier P (2017) Spatial and temporal response of wildlife to recreational activities in the San Francisco Bay ecoregion. Biol. Conserv. 207: 117-126. https://doi.org/10.1016/j.biocon.2016.11.003.

40. Riber AB (2006) Habitat use and behaviour of European hedgehog Erinaceus europaeus in a Danish rural area. Acta Theriol. 51, 363-371. https://doi.org/10.1007/BF03195183

41. Ridout MS, Linkie M (2009) Estimating overlap of daily activity patterns from camera trap data. J. Agric. Biol. Envir. St. $14: 322-337$. https://doi.org/10.1198/jabes.2009.08038

42. Robinson RA (2005) BirdFacts: profiles of birds occurring in Britain and Ireland (BTO Research Report 407). BTO, Thetford. Available from: $<$ http://www.bto.org/birdfacts>.

43. Rowcliffe JM, Carbone C (2008) Surveys using camera traps: are we looking to a brighter future? Anim. Conserv. 11: $185-186$. https://doi.org/10.1111/j.1469-1795.2008.00180.x

44. Rowcliffe JM, Kays R, Kranstauber B, Carbone C, Jansen PA (2014) Quantifying levels of animal activity using camera trap data. Methods Ecol. Evol. 5(11): 1170-1179. https://doi.org/10.1111/2041-210x.12278

45. Sidorovich VE, Sidorovich AA, Izotova IV (2006) Variations in the diet and population density of the red fox Vulpes vulpes in the mixed woodlands of northern Belarus. Mamm. Biol. 71(2), 74-89. https://doi.org/10.1016/j.mambio.2005.12.001

46. Soulsbury CD, White PC (2015) Human-wildlife interactions in urban areas: a review of conflicts, benefits and opportunities. Wildlife res. 42(7): 541-553. https://doi.org/10.1071/WR14229

47. Sollmann R, Mohamed A, Samejima H, Wilting A (2013) Risky business or simple solution - Relative abundance indices from cameratrapping. Biol. Cons. 159: 40-412. https://doi.org/10.1016/j.biocon.2012.12.025 
48. Steenweg R, Whittington J, Hebblewhite M, Forshner A, Johnston B, Petersen D, Shepherd B, Lukacs PM (2016) Camera-based occupancy monitoring at large scales: Power to detect trends in grizzly bears across the Canadian Rockies. Biol./ Conserv. 201: $192-200$. https://doi.org/10.1016/j.biocon.2016.06.020.

49. Storch I, Leidenberger C (2003) Tourism, mountain huts and distribution of corvids in the Bavarian Alps, Germany. Wildlife Biol. 9: 301 - 308. https://doi.org/10.2981/wlb.2003.018

50. Taylor K, Anderson P, Taylor R, Longden K, Fisher P (2005) Dogs, Access and Nature Conservation. English Nature Research Reports, Number 649, 157pp. http://publications.naturalengland.org.uk/publication/65013. Accessed 19 January 2021.

51. Triguero-Mas M, Dadvand P, Cirach M, Martínez D, Medina A, Mompart A, Basagaña X, Gražulevičienė G, Nieuwenhuijsen, MJ (2015) Natural outdoor environments and mental and physical health: Relationships and mechanisms. Environ. Int. 77(1): 35-41. https://doi.org/10.1016/j.envint.2015.01.012.

52. van der Zande AN, Vos $P$ (1984) Impact of a semi-experimental increase in recreation intensity on the densities of birds in groves and hedges on a lake shore in The Netherlands. Biol. Cons. 30: 237-259. https://doi.org/10.1016/0006-3207(84)90086-7

53. Welbourne DJ, Claridge AW, Paull DJ, Lambert A (2016) How do passive infrared triggered camera traps operate and why does it matter? Breaking down common misconceptions. Remote Sens. Ecol. Conserv. 2(2): 77-83. https://doi.org/10.1002/rse2.20

\section{Figures}
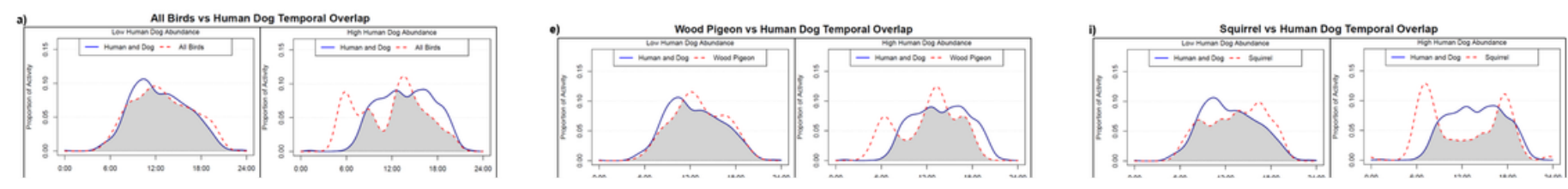

\section{Figure 1}

Activity schedules showing the temporal overlap between Human + Dogs (blue solid) and a) All Birds, b) Blackbirds, c) Magpies, d) Song Thrushes, e) Wood Pigeons, f) Non-diurnal Mammals, g) Red Foxes, h) European Hedgehogs and i) Grey Squirrels (red dashed) in low visit sites (left column) and high visit sites (right column). For number of detections for each species, see Online Resource-Table 4. Figures made in R v3.6.2 (R Core Team, 2019)

\section{Supplementary Files}

This is a list of supplementary files associated with this preprint. Click to download.

- BeasleyetalESM.docx 